\title{
DETECÇÃO DE CASEINOMACROPEPTÍDEO EM LEITE CRU
}

Daniella Rodrigues da Costa ${ }^{1}$, Dienisfer Silva dos Santos ${ }^{2}$, Ana Paula Borges da Costa $^{3}$, José Roberto da Costa Júnior ${ }^{4}$, Karyne Oliveira Coelho ${ }^{5}$

1- Médica Veterinária, Discente do Mestrado em Desenvolvimento Rural Sustentável da Universidade Estadual de Goiás (darocostavet@gmail.com) São Luiz de Montes

Belos - Brasil

2- Tecnóloga em laticínios

3- Zootecnista, Discente do Mestrado em Desenvolvimento Rural Sustentável da Universidade Estadual de Goiás

4- Zootecnista, Discente do Mestrado em Desenvolvimento Rural Sustentável da Universidade Estadual de Goiás

5- Médica Veterinária, Pós doutora em Ciência Animal, Docente do Mestrado em Desenvolvimento Rural Sustentável da Universidade Estadual de Goiás. Bolsista $\mathrm{BIP} / \mathrm{UEG}$

Recebido em: 03/10/2016 - Aprovado em: 21/11/2016 - Publicado em: 05/12/2016 DOI: 10.18677/EnciBio_2016B_034

\section{RESUMO}

O consumo de leite é essencial para o ser humano por possuir vitaminas e minerais essenciais ao desenvolvimento. A fraude por adição de soro de leite visa aumentar a rentabilidade. $O$ trabalho foi proposto com o objetivo de avaliar a presença de soro no leite cru coletados de galões sem controle de refrigeração, oriundos de dez municípios do estado de Goiás. O período de coleta foi de maio a agosto de 2015. Foram feitas análises físico-químicas para quantificação de soro de leite. Constatouse que $15 \%$ das amostras de leite cru apresentaram teor de CMP superior ao preconizado pela legislação, demostrando a necessidade de conscientizar os envolvidos na cadeia do leite quanto as boas práticas agropecuárias para produção de alimentos seguros e de qualidade.

PALAVRAS-CHAVE: Fraude, índice de CMP, soro de queijo.

\section{CASEINOMACROPEPTÍDEO DETECTION IN RAW MILK}

\begin{abstract}
The milk consumption is essential for humans to possess essential vitamins and minerals development. Fraud by adding whey aims to increase profitability. The work was proposed in order to evaluate the presence of serum in raw milk collected gallons without refrigeration control, coming ten municipalities of the state of Goiás. The collection period was from May to August 2015. Physicochemical analyzes were performed chemical for quantification of whey. It was found that $15 \%$ of the raw milk samples showed CMP content higher than that recommended by law, reflecting a need to educate those involved in the milk chain as good agricultural practices for production of safe and quality food.
\end{abstract}

KEYWORDS: Fraud, CMP index, cheese whey. 


\section{INTRODUÇÃO}

O leite é considerado um alimento com alto valor nutricional que compõe a alimentação de crianças, idosos e pessoas com debilidade imunológica, sendo um dos alimentos de origem animal mais consumido, o que torna a qualidade desse produto um ponto relevante para a segurança alimentar, pois diversas doenças podem ser veiculadas através do mesmo. Ainda, o leite dispõe de condições ideais para crescimento de microrganismos patogênicos (VIDAL-MARTINS et al., 2013). TOMBINI et al., (2012) e MUNIZ et al., (2013) relataram a importância do leite na alimentação humana em diferentes fases da vida, haja vista o mesmo possuir proteínas, gorduras, carboidratos, vitaminas e minerais essenciais para o organismo.

Devido a sua importância, a qualidade do leite e as fraudes ocorridas neste produto são uma preocupação constante das autoridades, sendo necessário o aperfeiçoamento das técnicas de detecção de fraudes para garantir a qualidade do leite que chega para o beneficiamento industrial (ABRANTES et al., 2014; ROSA et al., 2015). A adulteração do leite com acréscimo de água, soro ou qualquer outra substância causa alteração na qualidade e na quantidade de proteína, gordura, vitaminas, entre outras substâncias (ROCHA et al., 2015). Diante do exposto tornase cada vez mais necessário a utilização das boas práticas agropecuárias para produção de leite de maneira segura, pois só será possível a obtenção de um produto de qualidade, se a matéria prima utilizada também for de qualidade.

É admitido pela legislação brasileira o transporte de leite em latões, a temperatura ambiente. Para que isso seja aceito, há algumas normas a serem seguidas de acordo com a legislação vigente: $O$ estabelecimento processador deve concordar em trabalhar com esse tipo de matéria-prima; a matéria-prima fornecida deve atingir os padrões de qualidade fixados pela legislação; o leite deve chegar à indústria de beneficiamento em, no máximo, duas horas após a ordenha; o estabelecimento industrial que receber leite em latões deverá realizar todas as análises exigidas para leite por latão na legislação (BRASIL, 2008; BRASIL, 2011). Apesar da permissão, o transporte de leite a latão é dificultado pelas condições das estradas brasileiras, o que causa demora na entrega para as indústrias beneficiadoras (DA SILVA et al., 2011).

$\mathrm{Na}$ indústria, no beneficiamento do leite, é possível separar os componentes e produzir nata, manteiga, queijo e soro de leite que são denominados "matéria prima para subprodutos". Pesquisas na área demonstraram que uma tonelada de queijo rende nove toneladas de soro de leite (SPRINCHAN, 2009). Por ser considerado um subproduto, o soro de queijo tornou-se um protagonista nas fraudes em leite. A fraude por adição de soro no leite tornou-se corriqueira, devido a adição ao leite diminuir pouco a proteína do produto original, visto que o soro possui bastante proteína e o descarte pelas indústrias, no geral, é feito em desacordo com a legislação ambiental e polui o meio ambiente (PAIVA et al., 2015).

ABRANTES et al., (2014) explanaram que inicialmente adulterava-se o leite por adição de água com o objetivo de aumentar o volume, e por desnatação prévia com objetivo de produzir o creme de leite. Com o tempo surgiram novos tipos de adulterações, como adição de soro de queijo, de substâncias neutralizantes (hidróxido de sódio, bicarbonato de sódio e de potássio, soda cáustica), de substâncias conservantes (peróxido de hidrogênio, formol, ácido salicílico, ácido bórico, hipocloritos) e reconstituintes da densidade e crioscopia (sal, açúcar, amido).

Diversos autores como CAMPOS et al., (2011), KARTHEEK et al., (2011), ABRANTES et al. (2014) e MAREZE et al., (2015) mencionaram fraudes em leite, 
sendo que a fraude por adição de soro de queijo ao leite é feita para aumentar o volume e é um dos tipos de fraude em leite mais comum.

Em 2007 a Polícia Federal realizou a Operação "Ouro Branco" sobre a fraude em leite em duas cooperativas mineiras. No decorrer da operação foram recolhidas amostras de leite longa vida em todo o Brasil, pois a fraude envolvia diversas empresas em vários estados brasileiros. Em 2013, iniciou-se a Operação "Leite Compen\$ado", onde as investigações do Ministério Público do Rio Grande do Sul comprovaram que empresas gaúchas transportadoras de leite adulteravam o leite cru com adição de água e reconstituintes. Em 2014 o Ministério Público de Santa Catarina em conjunto com o MAPA iniciaram a Operação "Leite Adulterado I e II", todas com objetivo de combater diversos tipos de fraude em leite (BRASIL, 2016a, b, $c, d)$.

A legislação brasileira não permite que o leite possua sólidos do soro de queijo, assim diversos métodos foram desenvolvidos para a detecção deste tipo de fraude, sendo que a determinação do Glicomacropeptídeo (GMP), componente específico do soro, resultante da quebra da ligação peptídica da k-caseína entre os aminoácidos 105-106 Phe-Met, que resulta na formação da para-k-caseína(1-105) presente nas micelas de caseína e do glicomacropeptídeo (106-169) que fica no soro, são os melhores indicadores de fraude, pois estes componentes não são encontrados no leite. A cromatografia líquida de alto desempenho (HPLC) ou Cromatografia de exclusão molecular, que é uma técnica analítica e os métodos imunológicos também são usadas para pesquisar a fraude por adição de soro (BRASIL, 2006 a,b). O CMP também poderia ser denominado caseinoglicomacropeptídeo (CGMP), peptídeo derivado da caseína (CDP) ou ainda glicomacropeptídeo (GMP).

BRASIL (2006) estabeleceu que quando o índice de CMP estiver acima de 75 $\mathrm{mg} / \mathrm{L}$ o leite está considerado impróprio para o consumo humano e deverá ser destinado para alimentação animal ou para indústria química em geral. BRASIL (2014) declarou que amostras de leite que apresentarem concentração de CMP acima de $30 \mathrm{mg} / \mathrm{L}$ são consideradas amostras fraudadas com soro de queijo ou são de má qualidade, pois apresentaram intensa atividade proteolítica. Em face da importância de leite como alimento a ser consumido pelo ser humano, o trabalho foi proposto com o objetivo de detectar a presença de caseinomacropeptídeo em leite cru oriundo de municípios do oeste goiano.

\section{MATERIAL E MÉTODOS}

Foram analisadas 123 amostras de leite cru coletadas em galões sem controle de refrigeração, oriundo dos municípios Aurilândia, Caiapônia, Fazenda Nova, Firminópolis, Palmeiras, Palminópolis, Paraúna, São Luís de Montes Belos, Silvolândia e Varjão, todos no estado de Goiás. O período de coleta foi de maio a agosto de 2015.

Foram coletadas amostras de $350 \mathrm{~mL}$ de leite cru e armazenados em frascos previamente lavados e desinfetados de acordo com o recomendado pela instrução normativa $\mathrm{n}^{\circ}$ 62, do MAPA - Ministério da Agricultura Pecuária e Abastecimento (BRASIL, 2011). As amostras foram devidamente identificadas, acondicionadas em caixas térmicas e transportadas sob temperatura de $4,0 C^{\circ}$ ao laboratório de análise físico química para a verificação da presença do soro de leite, através da metodologia de espectrofotômetro, descrita da Instrução Normativa $n^{\circ} 68$ do MAPA (BRASIL, 2006a). 
Para a quantificação estimada de soro nas amostras de leite cru sem refrigeração, uma curva padrão foi construída utilizando-se uma amostra de leite cru reconhecidamente livre de caseinomacropeptídeo, a qual foi fracionada a fim de obter volumes de $10 \mathrm{~mL}$, os quais foram adicionados de soro nas concentrações de $0,0,1,0,2,0,2,5$ e 5,0\%. Para elaboração da curva padrão, foram adicionados sob agitação, $10 \mathrm{~mL}$ de solução de ácido tricloroacético (TCA) a 24,0\% em $10 \mathrm{~mL}$ de amostra de leite cru adicionadas de soro conforme descrito previamente, sendo 0 material homogeneizado e deixado em repouso por $30 \mathrm{~min}$, e os demais procedimentos conduzidos conforme Instrução Normativa ํㅡ. 68 (BRASIL, 2006a).

A absorbância a $470 \mathrm{~nm}$ foi determinada com a amostra resfriada a temperatura ambiente utilizando espectrofotômetro. Em seguida, a curva padrão dos valores médios de absorbância a $470 \mathrm{~nm}$, obtidos a partir de três repetições, frente a concentração de soro adicionado ao leite foi construída utilizando o programa Microsoft Excel. Com os resultados obtidos, foi feita análise estatística descritiva, percentagem de amostras em acordo com a legislação e os cálculos das frequências absoluta e relativa, empregando-se o programa Microsoft Excel 2010.

\section{RESULTADO E DISCUSSÃO}

Os resultados das análises estão apresentados na Tabela 1. Observaram-se 18 amostras positivas para a adição de soro de leite. Do total das 123 amostras analisadas, $85 \%$ apresentaram-se em conformidade com a legislação vigente, com teor de CMP variável entre 3,35 a $7,11 \%$, enquanto $15 \%$ das amostras apresentaram-se em desacordo.

TABELA 1 - Percentual de amostras de leite cru em desacordo quanto à adição de soro de leite

\begin{tabular}{lcccc}
\hline \multirow{2}{*}{ Análise } & \multicolumn{2}{c}{ Em acordo } & \multicolumn{2}{c}{ Em desacordo } \\
& $\begin{array}{c}\text { Freq. } \\
\text { Absoluta }\end{array}$ & $\begin{array}{c}\text { Freq. } \\
\text { Relativa }\end{array}$ & $\begin{array}{c}\text { Freq. } \\
\text { Absoluta }\end{array}$ & $\begin{array}{c}\text { Freq. } \\
\text { Relativa }\end{array}$ \\
\hline CMP & 105 & $0,85 \%$ & 18 & $0,15 \%$ \\
\hline
\end{tabular}

A qualidade do leite é um fator que preocupa o governo, os técnicos e a indústria, pois qualquer alteração na qualidade do leite, que é um produto largamente consumido pela população, pode levar a sérios problemas de saúde pública. FUSELLI et al., (2015) informaram que a qualidade do leite é um fator preocupante por questões de saúde e práticas comerciais, pois qualquer alteração na qualidade do leite, pode levar a sérios problemas de saúde pública.

O leite com adição de soro de queijo dá origem à bebida láctea e não pode ser considerado leite, e este produto não pode ser utilizado como se fosse leite puro, contudo a legislação brasileira permite a utilização do soro, não configurando fraude o seu uso de acordo com o permitido (PRATA \& PRATA, 2012). A fraude ocorre quando o leite se apresentar como de categoria superior, portanto adição de soro de queijo é fraude, pois compromete a qualidade e a composição do leite, sendo proibida a venda como leite puro (BRASIL, 2008) e a fraude por adição do soro de leite ocorrem principalmente pelo baixo valor comercial do soro e pelo alto custo do tratamento de efluentes antes do lançamento dos resíduos das indústrias lácteas nos corpos d'água (ROCHA et al., 2015).

CAMPOS et al., (2014) afirmaram que a água e o soro adicionados ao leite de forma dolosa alteram as concentrações dos constituintes sólidos do leite, o que 
configura a adulteração desse produto. KARTHEEK et al., (2011) e MAREZE et al., (2015) identificaram que a fraude em leite por adição de soro de queijo ocorre mundialmente e este tipo de fraude causa prejuízos financeiros para as indústrias, pois levam a diminuição do rendimento industrial dos produtos além de causarem sérios riscos para a saúde pública, pela possibilidade de veiculação de doenças através do leite.

FIRMINO et al., (2010) em estudo realizado na região de Rio Pomba - MG, em amostras de leite cru refrigerado, detectaram que $44 \%$ das amostras apresentaram adição de soro com percentual variável entre $0,81 \%$ a $11,74 \%$ e que as amostras com mais de $5 \%$ de adição de soro, houve também alteração da composição físicoquímica do leite ou também foram encontradas outras substâncias fraudulentas juntamente com a adição de soro. ROSA et al., (2015) em estudo realizado no município de Erechim - RS, avaliaram seis marcas de leite UHT integral e concluíram que $33 \%$ das amostras foram adulteradas com adição de soro de queijo. ALMEIDA et al., (2013) analisaram 3029 amostras de leite, onde 10,7\% apresentaram CMP acima de $30 \mathrm{mg} / \mathrm{L}$, mostrando-se assim em desacordo com a legislação para ser consumido como leite in natura.

TAMANINI et al., (2013) descreveram que a concentração do CMP no leite são características de fraude por adição de soro de queijo ou que o produto está deteriorado pela ação de microrganismos psicotróficos, logo a estocagem, a temperatura de refrigeração e o tempo de armazenamento influenciam no crescimento dos microrganismos que tem ação proteolítica e na concentração de CMP do leite, então a presença de CMP no leite não é confirmatória para fraude por adição de soro, pois esta molécula pode aparecer no leite devido a ação de bactérias psicotróficas sendo chamada de pseudo-CMP, que tem peso molecular semelhante ao CMP, porém apresentam uma molécula a menos que o CMP.

Nos animais com mastite causada por Pseudomonas sp. e Bacillus spp também ocorre a quebra da caseína por estes microrganismos com a liberação de peptídeos com ácido siálico e formação de pseudocaseinopeptídeo que podem levar a uma análise falso positiva para adição de soro ao leite (FIRMINO et. al., 2010, SOUZA et al., 2010 e CASSOLI et al., 2011).

TAMANINI et al., (2013) avaliaram 30 amostras de leite UHT, e todas foram negativas para adulteração por adição de soro de queijo, porém houve grande atividade proteolítica das bactérias confirmada com a presença de pseudo-CMP nas amostras. Porém nos estudos realizados por MENDES et al., (2010), BELOTI et al., (2011) e CAMPOS et al., (2011) não detectaram amostras fraudadas por adição de soro de queijo.

\section{CONCLUSÃO}

Das amostras analisadas um percentual significativo estava fora dos padrões de identidade e qualidade estabelecidos pela legislação brasileira o que reforça a necessidade de conscientização de todos os envolvidos na cadeia produtiva do leite sobre as boas práticas agropecuárias para produção de leite com qualidade e segurança. A fraude por adição de soro de queijo é uma prática ilegal e comum da cadeia produtiva do leite.

\section{REFERÊNCIAS}

ABRANTES, M. R.; CAMPELO, C. DA S.; SILVA, J. B. A. DA. Fraude em leite: Métodos de detecção e implicações para o consumidor. Revista do Instituto Adolfo 
Lutz, Juiz de Fora MG, v. 73, n. 3, p. 244-251, 2014. Disponível em: <http://revistas.bvs-vet.org.br/rialutz/article/view/27487.>doi:10.18241/007398552014 731611

ALMEIDA J.; BUENO, C. P.; DE MELO, C. S.; COELHO, K.O.; NEVES, R. B. S.; DOS SANTOS, A. P. P. Pesquisa de caseinomacropeptídeo (CMP) em leite cru como indicativo de fraude por adição de soro na microrregião de São Luís de Montes Belos - GO. Revista Veterinária e Zootecnia, Botucatu- SP, v20 (2 Supl 1), p. 326327, 2013.

BELOTI, V.; RIBEIRO JÚNIOR, J. C.; TAMANINI, R.; YAMADA, A. K.; CAVALETTI, L., SHECAIRA, C. L.; NOVAES, D. G.; SILVA, F. F. Qualidade microbiológica e físico-química do leite cru refrigerado produzido no município de Sapopema/PR. Revista Científica Eletrônica de Medicina Veterinária. São Paulo SP, n. 16 Janeiro de 2011. Disponível em: < http://faef.revista.inf.br/site/e/medicina-veterinaria16-edicao-janeiro-de-2011.html\#tab944>. Acesso em: 20 ago. 2016.

BRASIL. Ministério da Agricultura, Pecuária e Abastecimento. Instrução Normativa no 68, de 12 de dezembro de 2006. Oficializa os Métodos Analíticos Oficiais FísicoQuímicos, para Controle de Leite e Produtos Lácteos, em conformidade com o anexo desta Instrução Normativa, determinando que sejam utilizados nos Laboratórios Nacionais Agropecuários. Diário Oficial da União, Brasília DF, 14 dez. 2006a, Seção 1, p.8.

BRASIL. Ministério da Agricultura, Pecuária e Abastecimento. Instrução Normativa n69, de 13 de dez. 2006. Institui Critério de Avaliação da Qualidade do Leite in natura, Concentrado e em Pó, Reconstituídos, com base no Método Analítico Oficial Físico Químico denominado "Índice CMP", de que trata a Instrução Normativa n68, de 12 de dezembro de 2006. Diário Oficial da União, Brasília, 15 dez. 2006b Seção 1 , p. 67.

BRASIL. Ministério da Agricultura. Decreto $n^{\circ} 30.691$ de 29/03/1952 e alterado pela última vez pelo Decreto no 6.385, de 27 de fevereiro de 2008. Regulamento da inspeção industrial e sanitária de produtos de origem animal - RIISPOA. Diário Oficial da União, Brasília, DF, 27 fev. 2008. Seção 1, p. 10785.

BRASIL. Ministério da Agricultura, Pecuária e Abastecimento. Instrução Normativa 62. Regulamento técnico de produção, identidade e qualidade do leite tipo $A, 0$ regulamento técnico de identidade e qualidade de leite cru refrigerado, o regulamento técnico de identidade e qualidade de leite pasteurizado e o regulamento técnico da coleta de leite cru refrigerado e seu transporte a granel. Diário Oficial da União, Brasília, DF, 29 dez. 2011, Seção 1, p.6.

BRASIL. Ministério da Agricultura Pecuária Abastecimento. Laboratório Nacional Agropecuário - LANAGRO/RS. Método de Ensaio POA/04/03/01. Porto Alegre - RS, 13 de fevereiro de 2014.

BRASIL. Polícia Federal. Justiça condena acusados de adulterar leite presos na operação ouro branco. Disponível em: < http://www.pf.gov.br/agencia/noticias/2012/ 
marco/justica-condena-acusados-de-adulterar-leite-presos-na-operacao-ourobranco1 >. Acesso em: 03 ago. 2016 a.

BRASIL. Ministério Público Federal - MG. Procuradoria da República em Minas Gerais. Operação ouro branco desarticula quadrilhas que adulteravam leite. Disponível em: < www.prmg.mpf.mp.br/imprensa/noticias/criminal/operacao-ourobranco-desarticula-quadrilhas-que-adulteravam-leite >. Acesso em: 03 ago. 2016 b.

BRASIL. Ministério da Agricultura Pecuária e Abastecimento. Mapa continua investigação sobre fraude em leite. Disponível em: <http://www.agricultura.gov.br/ani $\mathrm{mal} /$ noticias/2013/05/mapa-apreende-dois-lotes-de-28-mil-litros-de-leite-cru>.Acesso em: 03 ago. 2016 c.

BRASIL. Ministério da Agricultura Pecuária e Abastecimento. Mapa Operação Leite Adulterado I e II. Disponível em: < http://www.agricultura.gov.br/animal/noticias /20 14/08/operacao-leite-adulterado-i-e-ii >. Acesso em: 03 ago. 2016 d.

BRASIL. Ministério da Saúde. Secretaria de Atenção à Saúde. Guia alimentar para a população brasileira. 2ª ed. Brasília - DF, 2014. cap. 3 p. 79-80.

CAMPOS, A. A. R.; ROCHA, J. E.S.; BORGO, L. A.; MENDONÇA, M. A. Avaliação físico-química e pesquisa de fraudes em leite pasteurizado integral tipo "c" produzido na região de Brasília, Distrito Federal. Revista Instituto de Laticínios Cândido Tostes, Juiz de Fora MG, v. 66, n. 379, p. 30-34, 2011. ISSN 2238-6416. Disponível em: <https://www.revistadoilct.com.br/rilct/article/view/159/167>. Acesso em: 02 ago. 2016.

CAMPOS M. T. M.; HOFF, R. B.; BARRETO, F.; ANDRADE, R. B. S.; LORENZINI, D.M.; MENEGHINI, L. Z.; PIZZOLATO, T. M. Detection and confirmation of milk adulteration with cheese whey using proteomic-like sample preparation and liquid chromatography-electrospray-tandem mass spectrometry analysis. Talanta. Amsterdam, v. 120 p. 498-505, 2014. Disponível em: < https://www.ncbi.nlm.nih.gov/ pubmed/2446802. .> doi: 10.1016/j.talanta.2013.11.093.

CASSOLI, L. D.; SARTORI, B.; MACHADO, F. The use of the fourier transform infrared spectroscopy to determine adulterants in raw milk. Revista Brasileira de Zootecnia, Piracicaba SP, v.40, n.11, p.2591-2596, 2011.

DA SILVA, I. C. V.; REIS, R. P.; GOMES, M. J. N. Custos e otimização de rotas no transporte de leite a latão e a granel: um estudo de caso. Organizações Rurais \& Agroindustriais, Lavras MG, v.2, n.1, p. 56-76, 2011.

FIRMINO, F. C.; TALMA, S. V.; MARTINS, M. L.; DE OLIVEIRA LEITE, M.; DE OLIVEIRA, A. D. M. Detecção de fraudes em leite cru dos tanques de expansão da região de Rio Pomba, Minas Gerais. Revista do Instituto de Laticínios Cândido Tostes, Juiz de Fora MG, v. 65, n.376, p. 5-11, 2010. ISSN 2238-6416. Disponível em: <https://www.revistadoilct.com.br/rilct/article/view/136/141>. Acesso em: 12 ago. 2016. 
FUSELLI, F.; DELUCA, A.; AMOMTEPELOSO, E.; IBBA, G. Detection of fraudulent addition of bovine whey in water buffalo ricotta cheese by isoelectric focusing. Journal of the Science of Food and Agriculture. New Jersey, v. 95, n. 13, p. 27572762, 2015. Disponível em: <http://onlinelibrary. wiley.com/doi/10.1002/jsfa.7019/abstract. > doi: 10.1002/jsfa.7019.

KARTHEEK, M.; SMITH, A. A.; MUTHU, A. K.; MANAVALAN, R. Determination of adulterants in food: A Review. Journal of Chemical and Pharmaceutical Research, India, v.3, n. 2, p.629-636, 2011.

MAREZE, J.; MARIOTO, L. R.; GONZAGA, N.; DANIEL, G. C.; TAMANINI, R. BELOTI, V. Detecção de adulterações do leite pasteurizado por meio de provas oficiais. Semina: Ciências Biológicas e da Saúde, Londrina PR, v. 36, n. 1, p. 283290, 2015. Disponível em:< http://www.uel.br/revistas/uel/index.php/seminabio/article /view/19258. doi: 10.5433/1679-0367.2015v36n1Suplp283.

MENDES, C. G.; SAKAMOTO, S. M.; DA SILVA, J. B. A.; JÁCOME, C. G. M.; LEITE, A. I. Análises físico-químicas e pesquisa de fraude no leite informal comercializado no município de Mossoró, RN. Ciência Animal Brasileira, Goiânia - GO, v. 11, n. 2, p. 349-356, 2010. Disponível em: <http://www.revistas.ufg.br/vet/article/view/1146/81 61.>doi: 10.526/cab.v11i2.1146.

MUNIZ, L.C.; MADRUGA, S.W.; ARAÚJO, C.L. Consumo de leite e derivados entre adultos e idosos no Sul do Brasil: um estudo de base populacional. Ciência \& Saúde Coletiva. Rio de Janeiro RJ, v.18, n.12 p. 3015-3522, 2013. Disponível em: <http://www.scielo.br/scielo.php?script=sci_arttext\&pid=S1413-81232013001200008. $>$ doi: http://dx.doi.org/10.1590/S1413-81232013001200008.

PAIVA, I. M.; DOS ANJOS, V. C.; BELL, M. J. V.; FURTADO, M. A. M.. Caracterização proteica de leite pasteurizado, soro de queijo e suas misturas pelo uso do analisador cem sprint ${ }^{\mathrm{TM}}$. Revista do Instituto de Laticínios Cândido Tostes. Juiz de Fora MG, v.70, n. 4, p. 192-199, 2015. Disponível em:< https://www.revistadoilct.com.br/rilct/article/viewFile/420/376.> doi: 10.14295/22386416.v70i4.420.

PRATA, L. F.; PRATA, C. B. Determinação de GMP e CMP* no leite por métodos espectrofotométrico (ANSM) e cromatográfico (HPLC)-parâmetros metodológicos ( ${ }^{*}$ glicomacropeptídeo e caseinomacropeptídeo). Archives of Veterinary Science. Londrina PR, v. 17, n.2, p. 29-39, 2012. Disponível em:< http://revistas.ufpr.br/veteri nary/article/view/16554.> doi: 10.5380/avs.v17i2.16554. 
ROCHA, P. C. A.; CUNHA, L. M. M.; MACHADO, A. V.; COSTA, R. O. Análises Microbiológicas do Leite e Tipos de Adulterações. Revista Brasileira de Agrotecnologia. Garanhuns PE, v. 5, n. 1, p. 01-06, 2015. Disponível em: < http://www.gvaa.com.br/revista/index.php/REBAGRO/article/view/3685>. Acesso em 10 ago. 2016.

ROSA, L. S. DA.; GARBIN, C. M.; ZAMBONI, L.; BONACINA, M. S. Avaliação da qualidade físico-química do leite ultra pasteurizado comercializado no município de Erechim-RS. Vigilância Sanitária em Debate: Sociedade, Ciência \& Tecnologia, São Paulo SP, v.3, n. 2, p. 99-107, 2015. Disponível em:< https://visaemdebate.incqs.fiocruz.br/index.php/visaemdebate/article/view/438.> doi: http://dx.doi.org/10.3395/2317-269x.00438.

SPRINCHAN, E. G. Optimization of technological regimes for obtaining proteinmineral concentrated products from secondary milk raw materials. Elektronnaya Obrabotka Materialov. Republic of Moldova, v. 45, n. 1, p. 73-80, 2009. Disponível em: <http://link.springer.com/article/10.3103/S1068375509010116.> doi: 10.3103/S1068375509010116.

SOUZA, A. H. P.; KATSUDA, M. K.; DIAS, L. F. Avaliação físico-química do leite UHT e pasteurizado comercializado na cidade de Londrina - PR. Revista Brasileira de Pesquisa de Alimento. Campo Mourão PR, v. 1. p. 39-42. 2010.

TAMANINI R.; RIOS, E. A.; PEREIRA, J. R.; RIBEIRO JUNIOR, J. C.; DA SILVA, L. C. C., BELOTI, V. Adição de soro de queijo em leites UHT produzidos na região sul do Brasil. Revista Veterinária e Zootecnia. Botucatu SP, v. 20 (2 Supl 1), p. 147148, 2013.

TOMBINI, H.; DALLACOSTA, M. C.; BLEIL, R. A. T.; ROMAN, J. A. Consumo de leite de vaca e derivados entre agricultores da região oeste do Paraná. Alimentos e Nutrição - Brazilian Journal of Food and Nutrition, Araraquara SP, v. 23, n. 2, p. 267-275, 2012.

VIDAL-MARTINS, A. M. C.; BÜRGER, K. P.; GONÇALVES, A. C. S.; GRISÓLIO, A. P. R.; AGUILAR, C. E. G.; ROSSI, G. A. M. Avaliação do consumo de leite e produtos lácteos informais e do conhecimento da população sobre os seus agravos à saúde pública, em um município do estado de São Paulo. Boletim de Indústria Animal, Nova Odessa SP, v.70, n.3, p.221-227, 2013. Disponível em:< http://revistas.bvs-vet.org.br/bia/article/view/11876.> doi: 10.17523/bia.v70n3p221. 